\title{
Is Feminist Literary Criticism Becoming Anti-Feminist?
}

\author{
Andrea Lebowitz
}

"I cannot speak well enough to be intelligible."

"Bravo! - an excellent satire on modern language."

Jane Austen, Northanger Abbey

Jane Austen eXpresses my dis-ease with the current state of feminist literary criticism. Born from the women's movement and committed to the goals of feminism, this body of work has literally exploded over the last decade. Although there is feminist literary criticism being produced by non-academics, the economics of production and publication have ensured that most of the material widely circulated is written by academics. As feminist literary criticism has gradually gained a foothold inside the academy, and as feminist critics have become more sophisticated in their analyses, the link to feminist goals has become less obvious. Indeed I fear that the critical theory and specialized language being employed by some critics have not only severed the connection to feminist ideals but actually turned against them. That is, by employing a language and theory unknown to the non-professional reader, a language and theory which can be exclusive, belligerent and anti-feminist, feminist critics may have turned their backs on the very readers for whom we supposedly exist. 
I was not fully aware of my own anxiety until I taught a course on feminist literary criticism. My students were every teacher's ideal: dedicated readers, committed to literature and what it can achieve, hard working. Without turning a hair, they ploughed through an enormous amount of critical and literary work. Always prepared and willing to discuss their perceptions and questions, they proved the old adage that the student teaches the teacher, and what they taught is that there is cause for alarm and anger over some of the feminist criticism being written. At first, they subscribed their uncertainty to their own lack of critical background. But as they became more adept at criticism, they concluded that there was an unwarranted and unnecessary degree of obfuscation and mystification in the language and theory some of the writers considered, who seemed more intent on proving critical prowess than clarifying critical questions. And they were right. Anger was not misplaced: it came not from the difficulty of the work but from the feeling that some critics had abandoned the original political purpose of their criticism. For both my students and I shared the belief that this new feminist criticism must be committed to articulating, changing and improving the lot of women. ${ }^{1} \mathrm{We}$ felt for example that an article which used the terminology and theory of another discipline like psychology or linguistics, without explaining either the theory or its usefulness for understanding the literature under consideration, had very little to do with feminist goals. This conclusion also applied to criticism which adopts the terms of an existing critical theory like structuralism without ensuring that the theory is accessible to the non-academic.

In any one of these instances anger is caused by the feeling that the original purposes of the criticism have been abandoned, since the belief that feminist literary criticism must be engaged has had profound implications on style and audience. It means that we should not address an exclusively academic readership. It means that we write in a style and language available to the non-academic. And most difficult of all it means that we attempt to avoid oversimplification or debasement of the literary text while still remaining clear in our discussions of complexity.

Another way to put this is that I believe that as academics and literary critics we must see ourselves first as teachers, using both the 
written and spoken word. ${ }^{2}$ The male academic establishment has always placed research and theorizing above teaching. Ideally there should be no split between these activities. Research should make us better, more sensitive teachers. But in the real world, theory and criticism are too frequently self-generated, self-defining and addressed only to the initiated. I am unalterably opposed to a hierarchy which places theory above the reach of the ordinary students, and further I believe that a teacher's primary responsibility is to her students. That teaching is often viewed as secondary has never seemed reason enough for me to change my priorities.

However, as feminist literary criticism has expanded and become more sophisticated in its questions and perceptions, we have had to face the fact that we are making greater demands on the preparation of our readers and students. In addition, it is tempting for the critic to move into a vocabulary and theoretical framework which shorthands the preliminary questions and makes her work easier but simultaneously reduces the number of people who can or will read the article. Alarmingly, then, the possibility of becoming just one more critical point of view addressed simply to those professionally engaged in the same undertaking, of becoming exclusive, elitist and anti-feminist, exists because of the development of ideas among feminist critics themselves as well as because of the pressure they feel to meet the challenge of the male critical establishment. What is to be done?

The first answer to the riddle rests in the definition of the reader. I think we must assume that the reader is a student, not necessarily one officially enrolled in any institution, but a reader who studies literature. This ideal reader knows literature because she reads and reads to find both a reflection of her own life and experience as well as new visions and understandings of that experience. Further she studies, not necessarily a formal course, but she is willing to puzzle over a piece of literature to work at it and to engage with it, for she hopes to find some answers or some explanation for her dissatisfaction with the work. Thus our reader is a student in the truest sense of the word, for she wants to know not simply for a grade or a degree but for her life. It is precisely because of her that I am writing.

The second answer demands an understanding of what has led us 
from the original goals of feminist literary criticism.

The main causes for the situation are best expressed in point form:

I. the pressure from critical establishments to prove our legitimacy

2. the internal development of questions within feminist literary criticism, which place greater demands on the reader and writer

3. the lack of theories of feminist literary criticism

4. the need to feather individual academic nests and careers in these times of austerity.

As I have suggested, not all feminist literary critics are academics, but the vast majority of work that circulates ${ }^{3}$ is produced by academics and consequently, for better or worse, academics control the quality of the work. These critics face two sets of demands and commitments - to their profession and to their political belief in the need for changing the status of women. These two mandates need not be in conflict, but right now because of the general social and economic climate, as well as the general state of critical theory in the academy, there is great tension between the two. Elizabeth Abel in the introduction to a special issue of Critical Inquiry ${ }^{4}$, "Writing and Sexual Difference," puts it this way. From the critical establishment of the academy comes the "litany of familiar accusations: reductiveness, dogmatism, insensitivity to literary values." But "sophisticated reading... may also generate a litany of new accusations: that textuality is simply a return to formalism; that feminist critics have betrayed political commitments in pursuit of academic credibility" (p. 174).

The first litany can and must be exposed, but in a roundabout way the very anti-feminism which inspires such an attack on feminist literary criticism is some reassurance that we are remaining true to our original goals. Not that I favour dogmatism or the reduction of literary complexities to simplistic political points, but such charges will be made regardless of the nature of our work, as long as the accuser feels that some bastion of control or power is being threatened. Thus to the degree that such accusations are inspired by disguised or hidden political belief, they can never be answered except by abandoning our commitments.

Naively we thought that as we became more skilled in our analysis we would be welcomed by our male colleagues. But is this realistic? If we continue to challenge male prerogative in the society, the criti- 
cal world, or the classroom, will we not meet with resistance from those who do not want to see change? Assuredly many male critics have been open to our ideas and have learned from them, but others have not. We must face the possibility that they quite possibly will not. As Jane Marcus points out:

It is not historical accident that the hegemony of the theoreticians and the valorization of theory itself parallels the rise of feminist criticism. While we have been doing literary housekeeping, they have been gazing at the stars. They refuse to bear the burden of the sins of their literary fathers or to make amends for centuries of critical abuse of women writers involving the loss, destruction, bowdlerization, or misevaluation of women's texts, diaries, letters and biographies. 5

It is time to acknowledge that we will not change those who refuse to recognize the male bias of traditional criticism. We must face this and stop spending our energies on trying to convince them, because we are being subverted by this endeavour.

As male supremacy has gathered itself into the bastion of theory, feminist critics have tried to storm the citadel by adopting male critical language and by applying every current theory to feminist criticism in order to prove we are capable of "real" literary criticism. We do not seem to realize that by doing this we continue to allow others to decide what we should be writing and, worse, in the process we lose our true language and audience. It is more important to consider the charge that we are abandoning our original goals than to prove we are "one of the boys."

Initially, feminist literary criticism was a type of sociological criticism. It took up the issues of sexual stereotyping within texts (usually those written by men); sexual discrimination within the writing and critical professions which hampered female authors, potential or actual; and the connections and reflections between the world of literature and the world of life. While this was the obvious place to begin, feminist critics quite quickly moved on to a concentration on works by women: to the uncovering of lost works and to the reinterpreting of known works by women. Again the development 
made sense, since it is obvious that our own experience would engage us and offer new scope for study. From the documentation of a female literary tradition, we went on to the next question of how it confronted, accommodated or subverted the dominant male tradition, and this in turn led us to draw the parallels between sexual differences (as seen in the world) and literary conventions (genres, images, themes, structures). Once engaged in such sophisticated literary readings, the next step was to ask if there is (or are) uniquely feminist literary theories for explaining female and male writing, since until recently feminist critics have largely adapted their methods and theories from existing (usually male) critics. Thus there is (from hindsight at least) a very clear logic and progression in the development of feminist literary criticism. ${ }^{6}$ We can see that the body of criticism was led by its own internal logic and that this logic led to more difficult and complex questions. There is no necessity that the later inquiry should be any less concerned with the larger questions of women's lives than the original observations. Then where is the problem?

Unfortunately textual analysis in some instances has become a formalism which not only disregards but ultimately denies political commitment, for in elaborating the complexities of the literary components of a work, some critics abandon any concern for the connections between literature and life. The critic is content to analyze an image or identify a theme without further comment. At this point, the criticism becomes covertly anti-feminist, since the condition of women (author or character-let alone reader) is no longer important. Once even a tenuous link with the larger world is lost, there is no reason not to employ a specialized language shared only by those engaged in similar studies. The pressure to do so is further encouraged by the desire to meet male critical standards which demands, as Marcus puts it, the "valorization of theory."

The unquestioning use of theories drawn from either literary criticism or other academic fields is fraught with difficulties. Most obviously there are individuals who are concerned with nothing more than their tenure and promotion and for whom the application of a currently "in" theory to the study of literature by or about women is just another part of the publish-or-perish game. But I firmly believe 
that most feminist critics are not feathering their nest and that their failed work is caused not by individual self-interest or greed so much as by the contradictions of the discourse and theory they have inherited and used uncritically.

Feminist literary criticism has lacked a single theory and, like much North American criticism written in English, has revised existing critical models. Critical theory, held in awe as the apex of endeavour, in practice is frequently an arid, mind-destroying enterprise incomprehensible to many trained academics, let alone non-academic readers and students. The sterility of much theoretical work enrages readers, yet its language is a tool of power and exclusion. Some readers, despite their anger, are intimidated into silence by fear that the problem is their inability to understand, rather than the obscurity of the critical language, and even those who attack such mystifying jargon are affected by it. Not surprisingly, feminist critics have questioned and revised existing methods and theories, often with great success, but this has not been without problems.

The feminist obsession with correcting, modifying, supplementing, revising, humanizing, or even attacking male critical theory keeps us dependent upon it and retards our progress in solving our own theoretical problems.... It is disheartening to find feminist critics still anxious for approval from the "white fathers" who will not listen or reply. Some feminist critics have taken upon themselves a revisionism which becomes a kind of homage. ... 7

I am concerned with what Showalter calls "homage," for it is this type of revisionism which is potentially most destructive, ${ }^{8}$ where the adulation of the "white father" is much more important than the original feminist goals. Again the desire to demonstrate theoretical expertise dominates, and to this is added the further ironic need to demonstrate this skill by praising a male mentor like Bloom, Burke or Lacan. Undoubtedly it is time to relinquish our dependence on the great masters and develop our own theory, but the first question to be asked is, can there be a single feminist theory?

Ultimately the intent of all present non-feminist theories is to 
demonstrate their superiority and truth. Consequently they are competitive, aggressive and exclusive of other theories, and as such diametrically opposed to the goals of feminism. I am concerned that in eschewing existing theories and attempting our own, we will fall victim to the same desire to compete with any rival theory, and feminist literary criticism will join the battle of the Titans. A further pitfall is the feminist attempt to employ a non-literary theory (for example, one drawn from psychoanalysis or anthropology) as model. While we can certainly learn from other disciplines, a slavish application of a non-literary theory really gets us no farther than revising a literary model. ${ }^{9}$ Indeed, it is worse. The text, if I can use the ana$\operatorname{logy}$, becomes another woman sacrificed to the mandate of a theory not intended for literary analysis.

Annette Kolodny has argued that the only answer to the question is eclecticism or pluralism.

Adopting a "pluralist" label does not mean, however, that we cease to disagree; it means only that we entertain the possibility that different readings, even of the same text, may be differently useful, even illuminating, within different contexts of inquiry. It means, in effect, that we enter a dialectical process of examining, testing, even trying out the contexts - be they prior critical assumptions of explicitly stated ideological stances (or some combination of the two) - that led to the disparate readings. Not all will be equally acceptable to every one of us, of course, and even those prior assumptions or ideologies that are acceptable may call for further refinement and/or clarification. But, at the very least, because we will have grappled with the assumptions that led to it, we will be better able to articulate $w h y$ we find a particular reading or interaction adequate or inadequate. This kind of dialectical process, moreover, not only makes us more fully aware of what criticism is, and how it functions; it also gives us access to its future possibilities.... To put it still another way: just because we will no longer tolerate the specifically sexist omissions and oversights of earlier critical schools and methods does not mean that, in their 
stead, we must establish our own "party line". ${ }^{10}$

Although Kolodny clearly does not wish to stifle debate, I am worried by the possibility that an unthinking eclecticism will silence useful disagreement and allow the most "acceptable" forms of feminist literary criticism to dominate while the radical are shunted to the periphery. In other words, critical positions which offer little or no challenge to sexist assumptions will be welcomed into the halls of academe while the more challenging will be excluded, unless we insist upon our differences and make them a real part of our debate.

Where does this leave us? Are we to be eternally consigned to the female pose of wringing our hands and bemoaning the absence of answers or have certain things become clearer?

We have arrived at this state of concern with textual analysis and theory by a logic inherent in our analyses as well as by the pressure of the external world. This state presents definite causes for alarm: the escape into a formalism which denies our original concerns, or the temptation to develop a mistress theory which will inherit the aggression and elitism of existing theory. Yet I do not see that we can turn from the task of freeing ourselves from our dependency on and homage to our borrowed master theoreticians. We are mistresses of our own house and we have followed a course of thought which makes sense. The need to develop our own theories of the relation of literature to society, our own cultural and literary theories, is real, but we must undertake the task for the right reasons, not simply to prove we can do it.

By the right reasons I mean the original goals - to understand and change the condition of women. Surely the desire to chart the literary expressions of women's lives, the ways men write about women, the ways women write about themselves, the ways women employ and confront literary as well as social conditions and conventions is related to the larger concerns of feminism. Although our inquiries have undoubtedly become more sophisticated and demanding as we have been propelled by the development of our own analysis, I see no reason why the present questions should be any less interesting to or useful for the non-professional reader, if we, the writers and teachers, choose to keep the audience in mind.

Much has been said about the communal nature of feminist liter- 
ary criticism: its dependence on collaboration, dialogue and support. These ideas are, however, undergoing severe stress. On the one hand we see statements of sisterhood which barely mask real difference, and on the other hand we see murderous attacks masquerading as criticism. We must find our way back to pluralism which tolerates and supports legitimate difference without repressing debate, which offers a way out of the wilderness of competition.

There is another and even more fundamental community to which we must return - the community between readers and writers. To my mind, feminist literary critics have tended to underplay this community while extolling the virtues of sisterhood among critics. The link between reader and writer, student and teacher, is after all the most fundamental of all, without which there is very little purpose. I do not wish to underestimate the demands we are placing on readers. I realize that we cannot supply easy answers, and we must ask our readers to be patient and attentive and involved in discussions which may not have immediate pragmatic application. However, I believe that readers will grant us this generosity, if we keep them in mind. Where feminist literary criticism has failed, it has done so because it lost touch with readers. My students' anger and my own stems from a sense that we are not really all that important to some critics.

If we hope to keep our work connected to the goals of feminism, if this is what we hope to accomplish through our work, we must be able to speak to our readers or we will become just another academic undertaking with its high priestesses and altar girls. The stakes are indeed high.

If... one continues to believe in the project of human speech, one must move beyond a view of language as simply or inexorably "power over," discourse as domination, or discourse as unavoidably masked, and toward speech as part of an emancipatory effort, a movement toward social clarity and self-comprehension. This does not and should not require a naive denial that language may be deployed to reinforce consensus and to shore up forms of domination by debasing the meanings of words, displacing our attention from the important to the trivial, or covering up with a smokescreen of obscurantisms that aim to deny and to distance. 
Still, the project of rational speech, an eyes-open, truthtelling passion against "the powers that be" and "the censors within," can be one emancipatory window into the future. ${ }^{11}$

Notes

1 Just one of the hundreds of examples of this dedication can be found in Gayle Greene, "Feminist and Marxist Criticism: an argument for alliances," Women's Studies, Vol. 9 (1981).

Feminist criticism is not necessarily criticism written by women or about women - though, of course, it may also be this. It is criticism which presupposes a feminist perspective, a perspective that both originates from and participates in the larger effort of feminism - the liberation of women from oppressive social structures and stereotypes. This is what is genuinely new about feminist criticism, its unique contribution and its sine qua non.... (p. 30).

${ }^{2}$ The role of the critic is essentially different from that of the writer. While creativity is undoubtedly involved in both kinds of writing, the critic's first responsibility is to clarify her perceptions, to act as a medium between the text and the reader. The need to be readily accessible to the reader is the critic's responsibility. To equate her work with that of the literary artist is confusing and to my mind inaccurate. Conversely, it would be wrong to apply my questions about feminist literary criticism to the literary work being done by women.

${ }^{3}$ The problem of getting work published and distributed is another major question beyond the scope of this article.

${ }^{4}$ Vol. 8, No. 2 (Winter 1981).

5 Jane Marcuse, "Storming the Toolshed," Signs, Vol. 7, No. 3, (Spring 1982) p. 624. 
${ }^{6}$ Although this is the overall development of the criticism, each type or "stage" continues to be pursued and to be of interest and use.

"Elaine Showalter, "Feminist Criticism in the Wilderness," Critical Inquiry, Vol. 8, No. 2 (Winter 198I), p. 183.

8This "homage" is what most enraged my students.

'Unfortunately after her brilliant exposé of the problems of revisionism, Showalter turns to an anthropological theory of dominant and muted groups as the potential basis for a new feminist theory.

10"Dancing through the Minefield: Some Observations on the Theory, Practice, and Politics of a Feminist Literary Criticism," Feminist Studies, Vol. 6, No. 3, (Spring 1980), pp. 18-19. I highly recommend this article, which is one of the classics of the criticism.

11Jean Bethke Elshtain, "Feminist Discourse and Its Discontents: Language, Power, and Meaning," Signs, Vol. 7, No. 3 (Spring I982), p. 605.

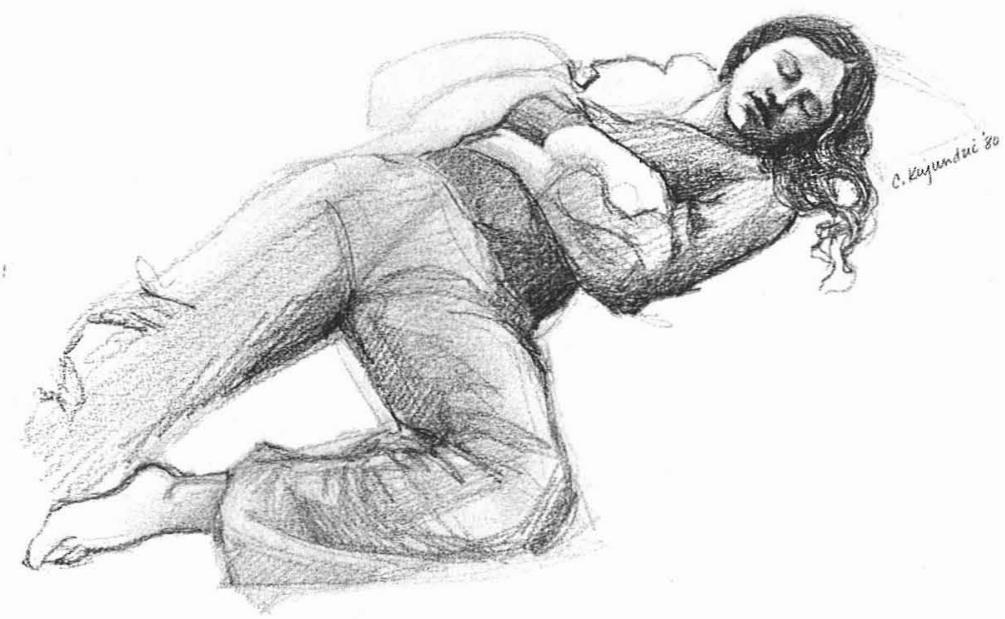

